\title{
Software for the Synergistic Integration of Science with ICT Education
}

\author{
Zhengyu Wu and Rainer E. Glaser \\ University of Missouri-Columbia, Columbia, MO, USA
}

zw46C@mizzou.edu glaserr@missouri.edu

\section{Executive Summary}

The realization of information and communication technology (ICT) literacy is a global and complex objective. It has been argued that it cannot be accomplished by single-focused, stand-alone curricula. Instead, it has been recommended that ICT education be integrated into the instruction of other disciplines to effectively promote technical proficiency, discipline knowledge acquisition, and cognitive development. The Chemistry Is in the News (CIITN) Project exemplifies this integration through the combination of advances in chemistry teaching, chemical informatics, and the educational use of ICT.

CIITN is an innovative curriculum that aims at the development of scientific, ICT, and media literacy by the engagement of the students in learning activities that are based on authentic news media, that parallel the research process, and are conducted in collaborative groups. The CIITN activities consist of the study, creation, and peer review of online CIITN portfolios. A CIITN portfolio consists of an electronically published news article from the actual online media, interpretive comments, pertinent links, references to primary sources, and questions.

The CIITN webtool is designed to minimize time and effort associated with non-intellectual and technical aspects of the CIITN project for both students and instructors. Combining the power of data integration provided by database management system technology with the real-time multiuser access functionality of the Internet, the CIITN webtool enables and guides student teams to create and submit group projects, access group projects created by other teams, and complete peer evaluations (both inter- and intra-group). The design of the CIITN webtool parallels and supports the functionalities defined and requested by the philosophical, pedagogical, and organizational foundations of the CIITN Project.

The underlying ideas are transferable and the CIITN Project and CIITN webtool can easily be adopted by other academic disciplines at any educational level. A preliminary assessment of the webtool was performed and is reported. The authors will provide software and portal space on the authors' machine free of charge to readers of JITE.

Keywords: Science Education, Lifelong Learning, Learning for Life, Computer-Assisted Collaboration and Communication, Scien-

Material published as part of this journal, either on-line or in tific Literacy, Media Literacy, ICT print, is copyrighted by the publisher of the Journal of Information Technology Education. Permission to make digital or paper Literacy, Science Writing, Peer Review, Database Management System.

copy of part or all of these works for personal or classroom use is granted without fee provided that the copies are not made or distributed for profit or commercial advantage and that copies 1) bear this notice in full and 2) give the full citation on the first page. It is permissible to abstract these works so long as credit is given. To copy in all other cases or to republish or to post on a server or to redistribute to lists requires specific permission and payment of a fee. Contact Editor@JITE.org to request redistribution permission. 


\section{Introduction}

In 1996, the Advisory Committee to the National Science Foundation Directorate of Education and Human Resources issued its Review of Undergraduate Education entitled Shaping the Future-New Expectations for Undergraduate Education in Science, Mathematics, Engineering, and Technology. The key recommendation to Science, Technology, Engineering, and Mathematics (STEM) faculty was to "model good practices that increase learning; start with the student's experience, but have high expectations with a supportive climate; and build inquiry, a sense of wonder and the excitement of discovery, plus communication and teamwork, critical thinking, and life-long learning skills into learning experiences.” Shaping the Future charges college-level science educators to use technology effectively to enhance learning and communication and to develop curricula "that take full advantage of modern technology, particularly personal computers, multimedia materials, digital libraries, hypertext links, and access to vast networked resources, including databases and activities on other campuses.” Recent innovations in computer technologies, particularly in computer-mediated communication via the Internet, are being increasingly used as resources to enhance teaching and learning in the college classroom (Capri, 2001; Carnevale, 2003; Chasteen, 2001; Stone, Bongiorno, Hinegardner, \& Williams, 2004; Towns \& Zielinski, 2004).

Educators and administrators also agree that it is essential for citizens in a democratic society to understand and make informed decisions about various, political and economic choices. Many of these choices require scientific literacy, which requires an understanding of concepts and principles underlying current issues. This demands awareness of the context, compelling the integration of real-world elements into every classroom.

The higher goals of science education and policy are thus well defined and the significance and importance of achieving these goals have been widely accepted. The challenge at this time concerns the design, implementation, and assessment of teaching methods that accomplish this ambitious goal in a systematic fashion. These methods should be fit for widespread adoption so as to serve as teaching tools that can affect systemic change. With the Chemistry Is in the News (CIITN) Project, we are addressing this challenge in the context of college science instruction (Borman, 2004; Leslie, 2004). It is the objective of the CIITN Project to facilitate learning activities based on authentic news media in small collaborative groups particularly in the context of large lecture setting. The CIITN activities consist of the online study, creation, and peer review of CIITN portfolios, which consist of (a link to) an electronically published news article from online media, particularly the popular press, interpretive comments, pertinent links, references to professional journals, and questions.

To accomplish these complex learning activities, one must rely on and further develop the ICT literacy of the students and their instructors. ICT literacy is a worthwhile objective in and of itself because students must be prepared to access and use information to make the decisions demanded of them as citizens of a democratic society. However, stand-alone ICT education falls short of achieving real ICT literacy as "it was becoming abundantly clear that unless students could integrate information technology in with other cognitive skills, it was really not causing any transformation in their learning," (O’Conner et al., 2002). This insight calls for the combination of ICT education with discipline content knowledge. It is this combination of science content and IC technology found in the CIITN Project that exemplifies well the new paradigm of teaching ICT literacy as advocated in Digital Transformation (O’Conner et al., 2002).

CIITN connects abstract scientific concepts with real world experience and constructivist learning theory (Bodner, Klobuchar \& Geelan, 2001; Taylor, Gilmer \& Tobin, 2002) holds that such connections can help motivate students to learning and remember the content. Yet, the automatic adoption of CIITN is far from being assured based on these disciplinary strengths alone. The im- 
plementation of the CIITN Project without a project-specific webtool created more work for the instructor, most of which involved time-consuming class organization, project management, and information exchange; this work increases with class size. Therefore an automated system was needed as a tool to support the sustained implementation of CIITN project. The webtool facilitates the CIITN Project in three major arenas. First, it allows for the integration of the project into a large class with minimal additional input of time on the part of the instructor because the class organization and project management is carried out largely though the automated system. Second, the webtool facilitates the transferability across institutions and easy adoption by other instructors. Third, the webtool is essential for cross-campus collaboration because it (1) replaces paperbased projects, (2) provides a easily accessible venue to all participants, and (3) allows for the speedy transmission of information, including projects, comments, and scores.

The CIITN webtool is a database-supported web interface with built-in functionalities that support CIITN activities, including the creation of CIITN projects, peer review and score reporting. The web interface of the CIITN webtool is located at http://ciitn.missouri.edu and the home page is shown in Figure 1. The webtool provides open access to informational items via the menu on the left. Access to the CIITN functions requires login via the horizontal toolbar on top, and there are login options for faculty, student groups, individual students, and the site administrators.

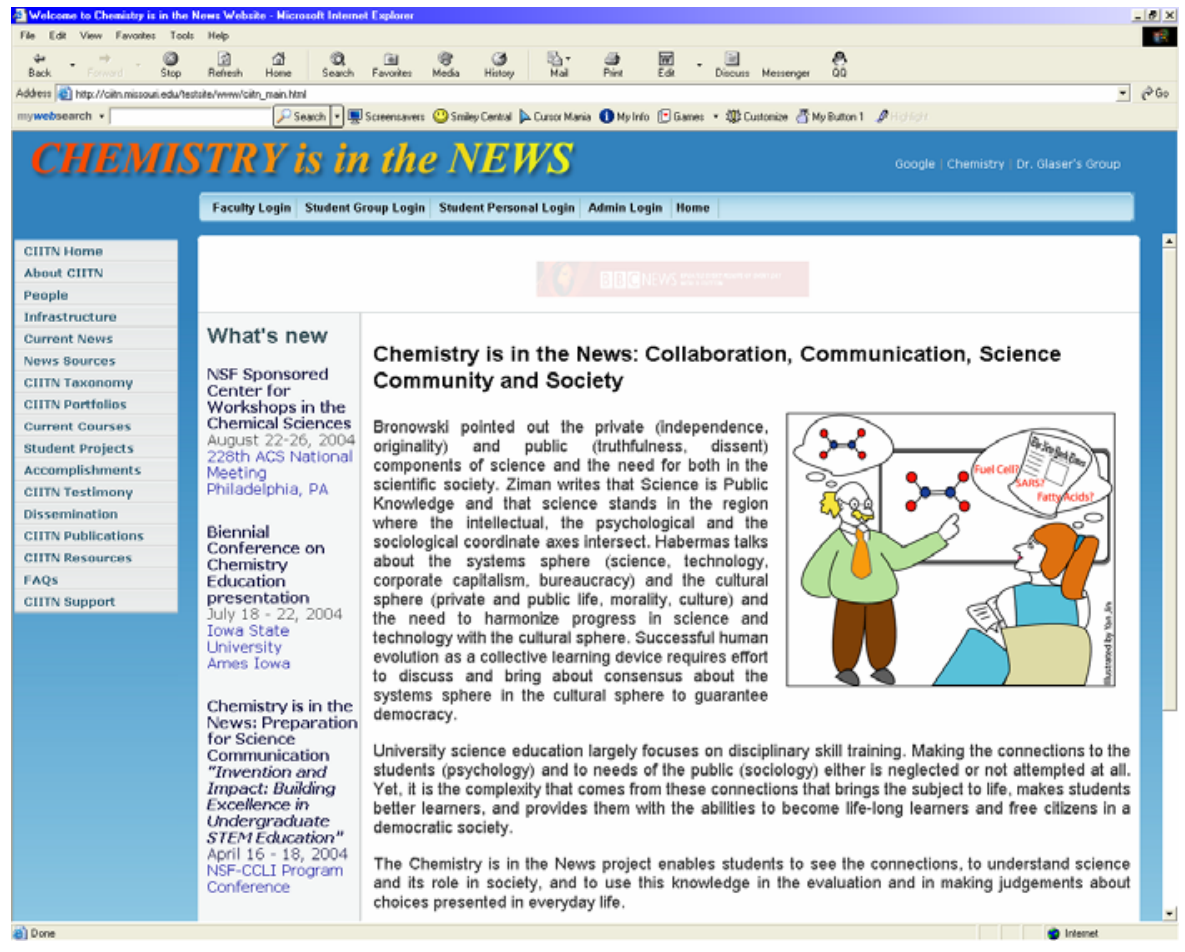

Figure 1: CIITN Web Interface.

\section{Taxonomy of CIITN Learning Activities}

We have been studying the incorporation of the news media based learning activities in teaching of sophomore organic chemistry since 1997. It is our goal to engage students in a full range of cognitive skills from the acquisition of knowledge and the development of comprehension to application, analysis, synthesis, and evaluation (Bloom, Engelhart, Frost, Hill, \& Krathwohl, 1956). We realize that the elements of the Bloom taxonomy are not strictly hierarchical (Biehler \& Snowman, 1986) and aim to setup a co-evolutionary spiral that improves all elements over time. 
To reach this goal, we have developed a systematic teaching approach (Glaser, 2003; Glaser \& Carson, in press; Glaser \& Poole, 1999; Hume, Carson, Hodgen, \& Glaser, 2004). This teaching innovation involves six levels to guide instructors in the stepwise implementation in their classes. The teaching-and-learning activity levels and the related activities are shown in Table 1 . We have accomplished level-1 through level-5 activities and we are currently embarking on level-6 activities.

Table 1: Taxonomy of Authentic News Media Based Learning Activities

\begin{tabular}{|c|c|c|c|c|}
\hline Level & Activity & Quality Review & Resource & Focus \\
\hline 1 & Read News Article & None & $\begin{array}{l}\text { Online News } \\
\text { Media }\end{array}$ & $\begin{array}{l}\text { Issue Awareness } \\
\text { \& Interest }\end{array}$ \\
\hline 2 & Read News Portfolios & None & \multirow{2}{*}{$\begin{array}{l}\text { CIITN Online } \\
\text { Database }\end{array}$} & $\begin{array}{l}\text { Knowledge \& } \\
\text { Comprehension }\end{array}$ \\
\hline 3 & $\begin{array}{l}\text { Read \& Create News } \\
\text { Portfolios }\end{array}$ & $\begin{array}{l}\text { Instructor Re- } \\
\text { view }\end{array}$ & & $\begin{array}{l}\text { Application, Analysis } \\
\text { \& Synthesis }\end{array}$ \\
\hline 4 & $\begin{array}{l}\text { Read, Create \& Judge } \\
\text { News Portfolios }\end{array}$ & $\begin{array}{l}\text { Intra-class Peer } \\
\text { Review }\end{array}$ & \multirow{3}{*}{$\begin{array}{l}C I I T N \text { Soft- } \\
\text { ware Tools }\end{array}$} & $\begin{array}{l}\text { Evaluation, } \\
\text { Constructive Review }\end{array}$ \\
\hline 5 & $\begin{array}{l}\text { Read, Create \& Judge } \\
\text { News Portfolios }\end{array}$ & $\begin{array}{l}\text { Inter-class Peer } \\
\text { Review }\end{array}$ & & Awareness of Diversity \\
\hline 6 & $\begin{array}{l}\text { Read, Create \& Judge } \\
\text { News Portfolios }\end{array}$ & $\begin{array}{l}\text { International } \\
\text { Peer Review }\end{array}$ & & $\begin{array}{l}\text { Awareness of Interna- } \\
\text { tional Context }\end{array}$ \\
\hline
\end{tabular}

Students start working on their CIITN projects by reading and answering the questions from instructor-created portfolios, which follow along with the course and are integrated into lecture, discussions, and exams. Next, students work together in their groups to create their own portfolio. This requires students to explore a wealth of news media resources in order to select an article and other sources. Then students write interpretive comments that include links to high-quality web sites and links to animations, graphics and movies to place the material in context and supply background information, and finally write and answer their own questions. The addition of questions to portfolios makes the learning activity much more active. Well-selected questions can provoke critical thinking about the presented material and its societal, economic, and environmental consequences, and answering the questions also requires a more in-depth analysis and evaluation of the material. Finally, students engage in two rounds of peer review, constructive and final peer review. In this stage, they read and assess portfolios created by other groups, assigning scores and providing justification. Peer assessment has long been used in writing courses as well as in a variety of other fields (Bonwell \& Eison, 1991; Freeman, 1995; Rafiq \& Fullerton, 1996; Russell, Chapman \& Wegner, 1998). This research has shown that peer evaluation supports collaborative group work in general and, in particular, it supports a shift in students' perspective from writing for the teacher to writing for their peers and, ultimately, for a larger audience. Since these projects are to be published online for all the world to read, it is appropriate that they are reviewed by peers. In addition, peer review is another form of communication (Barka \& Barka, 1996; Kelter, Jacobitz, Kean, \& Hoesing, 1996) that trains an essential aspect of the scientific process. Students learn that the rigor inherent in the scientific analysis is diminished when com- 
plex real-world situations are analyzed. The first round constructive peer review provides the students with the opportunity to revise their portfolios. The score from this round of peer review is not factored into students' final grade. A score from the second round (final) peer review is the final score of a student group's CIITN project.

To cap off the process, students engage in an examination of how well the group worked to create their project. They assess their group members through intra-group peer review at the end of the semester. This process is meant to prevent freeloading and help students reflect on the process of collaboration and improve their collaborative skills.

\section{Why Use a Webtool in Teaching?}

Since its birth, the World Wide Web has been changing the way people communicate and work in profound ways. People can access a website from everywhere in the world with Internet connections. As pointed out by Whatley, the benefits of applying Internet technology for learning includes "provision for disadvantaged students as well as cost savings through economies of scale or automation of the teaching processes; also embracing video, audio and animation may help the learning process" (Whatley, 2004). Combined with database technology, a website can collect, maintain, process and integrate large amount of information as well as facilitate fast online communication, therefore providing users with an easy and secure work environment. Furthermore, many undergraduates expect the integration of technology into their coursework because of the increased use of computer technology at the K-12 level.

It is the purpose of the CIITN webtool to help and guide student teams to create and submit group projects, access other group projects, complete peer evaluation (both inter-group and intra-group). The webtool also enables instructors to handle all the aspects related to the CIITN activities online, including managing student groups and individuals, retrieving group projects, tracking evaluation processes, and accessing student grades. It is our goal to minimize the time and effort on non-intellectual and technical aspects of the CIITN project for both students and instructors.

Users of the CIITN webtool do not need to install an application software; users only need to have a computer equipped with a web browser. Though students are encouraged to work with their teammates closely instead of working on their own, the CIITN webtool does support real-time multi-user access from different computers due to the basic characteristics of web interfaces. This feature gives the CIITN webtool greater flexibility to expand to support long distance learning. While long distance learning usually refers to the students studying in isolation and usually also off-campus (Rudenstine, 1997), modern educational practices in traditional settings include "long distance learning” activities. For example, in our practice, students in universities in different states have participated in the same "CIITN course" in which they peer review each others' group projects.

It is another important feature of the CIITN webtool that it is not limited to applications in the teaching of sophomore organic chemistry. The webtool is designed so that it is easily adaptable to any discipline, science or non-science, that involves team projects and/or peer reviews. In fact, courses involving such activities traditionally have been in the areas of computer engineering, computer science, and business. The webtool also is easily adaptable to various levels of instruction, including graduate courses, lower- and upper-division college courses, as well as high school courses.

\section{Design of the CIITN Webtool}

The CIITN webtool has a web interface (http://ciitn.missouri.edu) as its front-end and an Oracle database as its back-end. The web interface uses Perl CGI scripts to communicate with and transfer data to and from the database. The CIITN website and its database are located on two Unix 
servers hosted by the University of Missouri-Columbia's Information Access and Technology Services (IATS).

The design of the CIITN webtool is based on the teaching model that we have been developing (Table 1). As was pointed out above, it is our goal to enable the easy adaptation of the CIITN webtool to other science and non-science disciplines and to different levels of education. Therefore, we designed a database that is general in its scope, restrictions, and functionality. The database has two major functions: (I) storing data, such as user information and project information; (II) maintaining the basic logical relations among students, student groups, and instructor(s). The design of the web interface responds directly to the functionalities required by the model shown in Figure 2. The CGI scripts run by the web interface are independent packages. This also gives instructors great flexibility to choose the functions they need as well as to customize current CGI scripts or to program new ones.

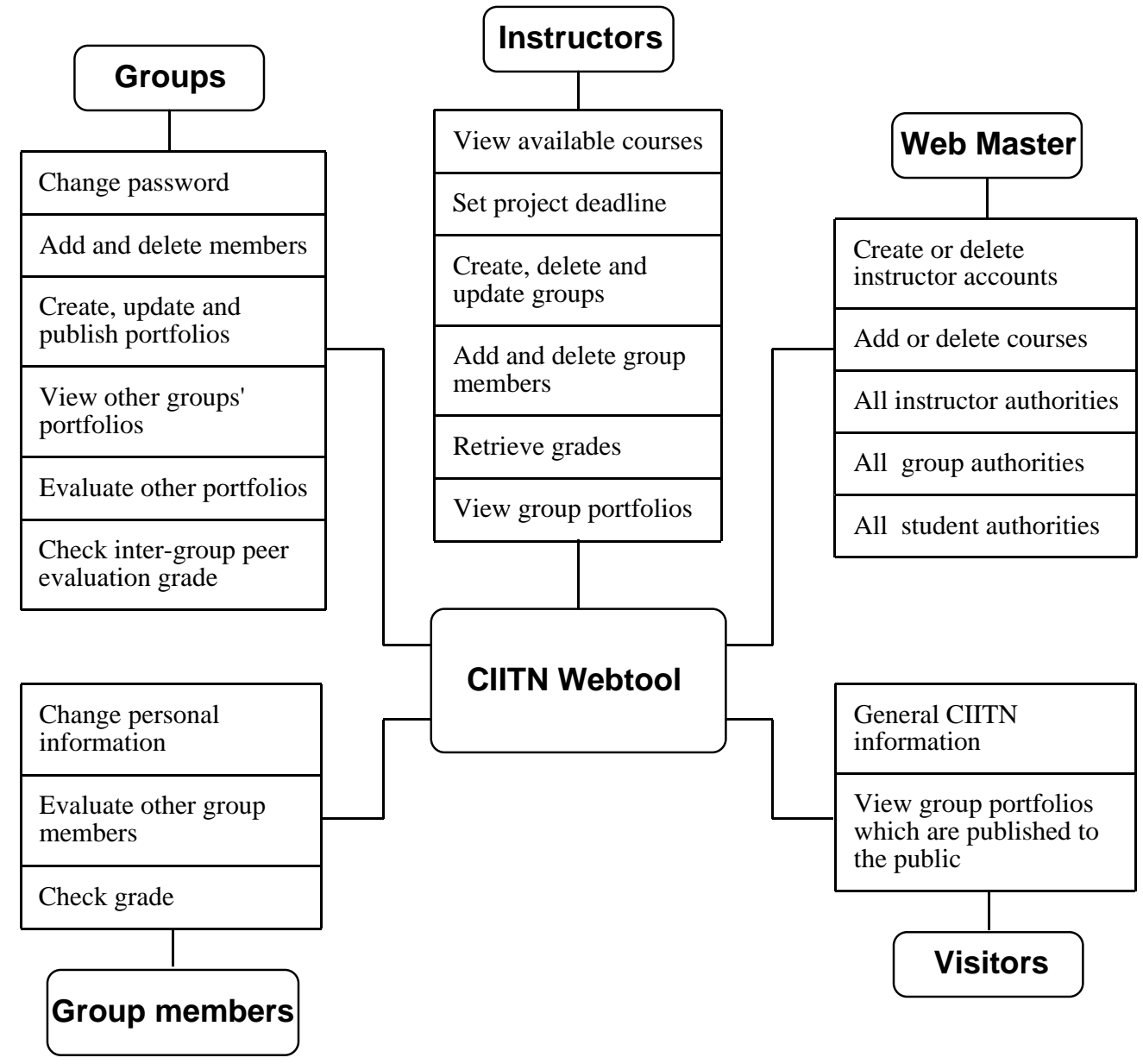

Figure 2: CIITN Webtool's Functionality

\section{Design of the CIITN Database}

The CIITN database is hosted by a Unix server running the Oracle9i enterprise edition release 9.2.0.4.0. The database query language is SQL 92. In the development of the database management systems (DBMS) for the CIITN webtool, we considered the following important issues out- 
lined by Ramakrishna and Gehrke (2000): data independence, data integrity and security, data administration, concurrent access and crash recovery, and application development time.

With regard to data administration it is important to minimize data redundancy and fine-tune the storage of the data to make retrieval efficient because different users access the same data. For example, all the members of a group will have the same final project score. We can store this score for every group member. However, this means the same score will be stored multiple times and thus will make updating the score inefficient (scores might be updated multiple times) and some times even create errors (some are updated, while others might not).

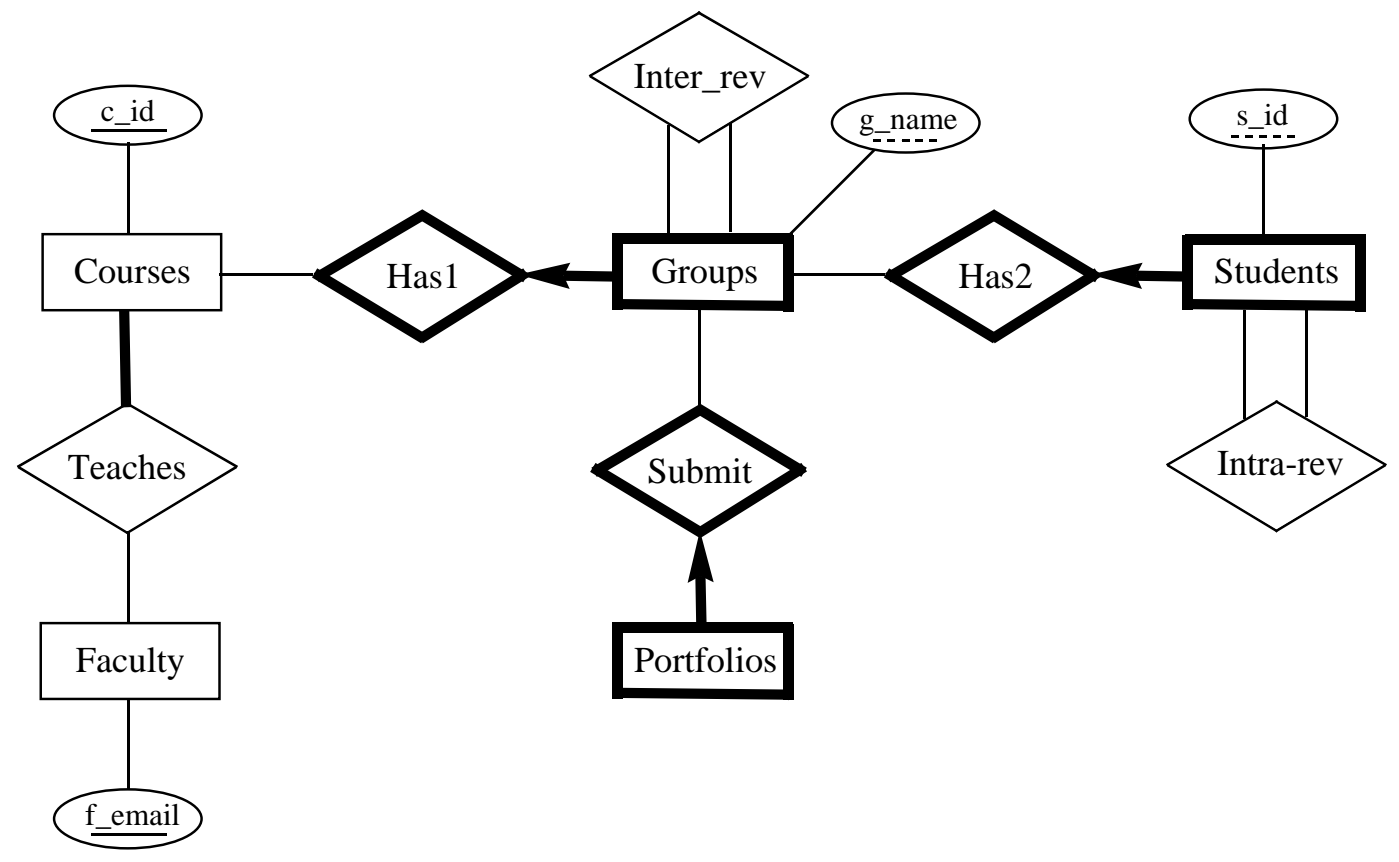

Figure 3: The Entity Relational Diagram of the CIITN Database Design. Only the key attributes are shown.

With respects to application development time, a database management system (DBMS) offers the advantage that many important tasks can be handled by the DBMS instead of by the application. In our specific case, however, this is a disadvantage. If the DBMS were implemented so that it would do most of the specific queries requested by the CIITN projects, its functionality would be limited. Therefore, we implemented most of the functionality with the CGI scripts instead of asking the DBMS to do so.

At this point, we have identified the requirements of the DBMS. Except for the above practical issues, the basic structure of a DBMS is the conceptual description of the entities to which the data belong and their relationships. The basic entities in a college class are students, student groups, and faculty members/instructors. The CIITN database should keep all the information of these entities related to the CIITN project. Therefore the second step is to develop a high-level description of the data to be stored in the database, along with the integrity constraints. To do so, we employed the entity-relationship (ER) model and this conceptual database design is shown in Figure 3. 
The CIITN DBMS contains five entities. Except for the faculty and courses, the projects, groups and students entities are all weak entities, which means they are dependent upon the identifying owner to whom they belong. For example, a group is dependent upon a particular course. A group can only be identified by the combination of the partial key g_name (group name) and the primary key c_id (course id) of the course entity. Whenever its owner course is deleted, the group will be deleted as well. Imposing this constraint ensures that every group in the database belongs to one and only one owner course and avoids assigning the same group to multiple courses by input mistakes. Such constraints can also be found with "students" and "projects" entities.

A faculty member can exist in the CIITN database without association to any course as shown in Figure 2. However, every course has to belong to at least one faculty member. We do allow multiple faculties to be associated with the same course to facilitate inter-state or international collaborations (CIITN level-5 and level-6).

Aside from the five entities, two relation tables are created in the database. The tables inter_rev (inter-group peer evaluation) and intra_rev (intra-group peer evaluation) keep records of the interand intra-group peer reviews.

The third and last step of the database design involves the logical database design in which the conceptual database design is converted to a database schema in the data model of the chosen DBMS. There are various data models to define the data to be stored. We used the most popular relational data model and today's database management systems, including Oracle, are based on this model.

\section{Design of the CIITN Web Interface}

The CIITN web interface was designed following the general guidelines put forth by Forsythe, Grose and Ratner (1998) to best accommodate the human factors of the CIITN project. Based on the functionality requirements of the CIITN projects shown in Figure 1, the users are classified into five categories. They are faculty/instructor(s), student groups, individual students, visitors, and webmaster. We will only discuss the web interface design for faculty/instructor(s), student groups, and students; the participants in the teaching-and-learning processes.

\section{Faculty/Instructors' Interface}

The faculty/instructor(s) interface is shown in Figure 4. An instructor starts using the CIITN webtool by contacting the webmaster with the request to open an account and to create a course in the database. Through his/her personal account, an instructor will have full access to his/her CIITN courses. An instructor may choose to collaborate with (an)other instructor(s) in a "joint course" in which students from different classes peer-review each other. In such a course, an instructor will be able to access the scores of the students of the class(es) of the collaborating instructor(s) only with approval from the respective Institutional Review Boards (IRB). Otherwise, an instructor can access just the scores of the students in his/her class.

After a new course has been setup, the instructor needs to create student groups. This task requires the entry of group names. The database will automatically generate a group number and password for every group. These passwords will be sent to individual student groups so that they will gain immediate access to their accounts. After this step, the student groups and individual students can begin to work the CIITN portfolios. Instructors do not have to be involved in the creation and evaluation of the CIITN portfolios.

An instructor can setup and change the deadline for the submission of group projects (optional), manage (add, delete or update) groups and group members, retrieve course grades, and view CIITN projects online. 


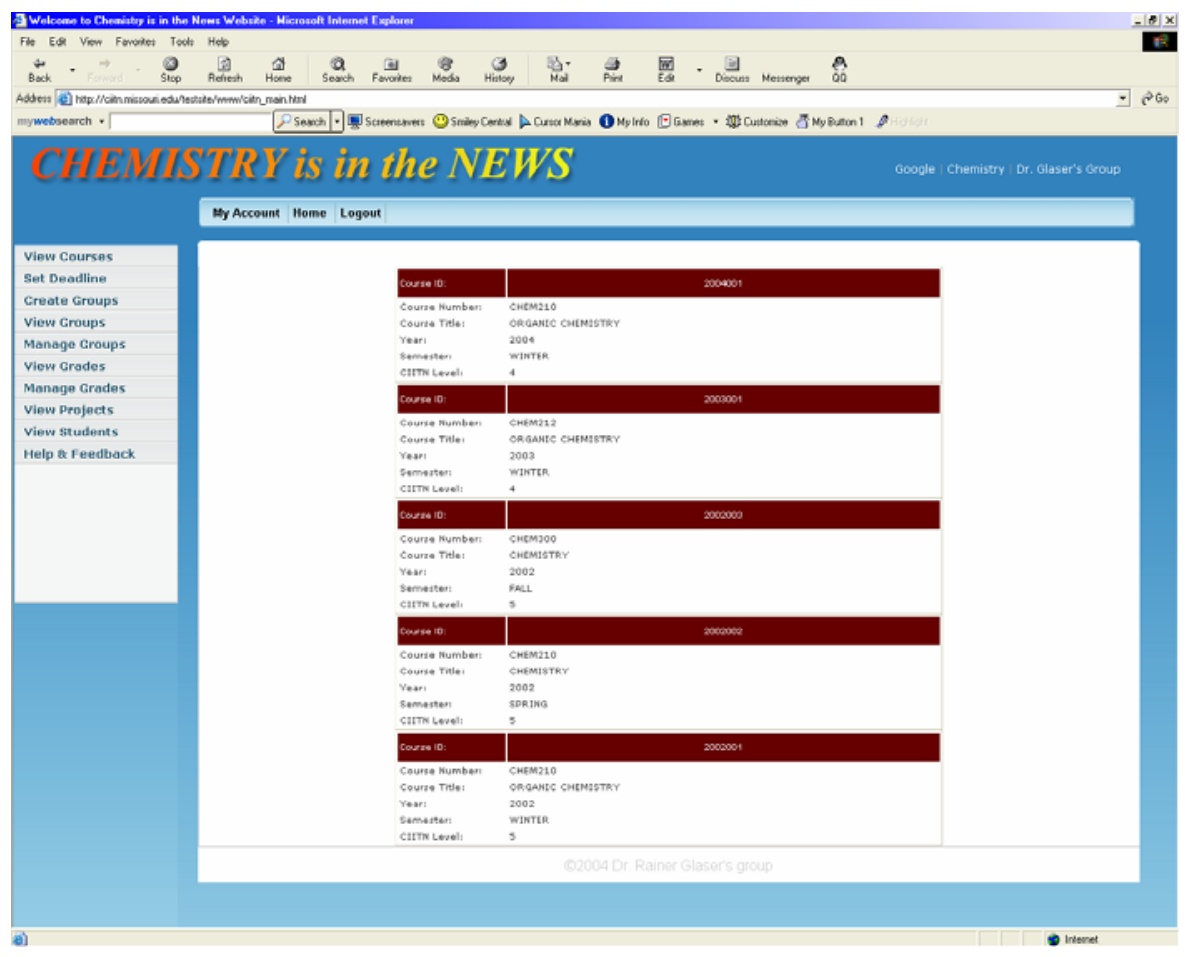

Figure 4: The Faculty/Instructors’ Web Interface.

\section{Student Groups' Interface}

Students are responsible for finding group members and forming their groups. After a student group has been created in the database by an instructor, the group can login into its account by the default password generated by the CIITN webtool. The student groups' interface is shown in Figure 5. The group can change their group login password, update group information, add or delete group members, and create or update their group project.

Student projects are collected by the web interface through an html form with text fields requesting corresponding information such as the project title, the link to the news item, and the interpretive comments. The text entered into these text fields are saved in the database as character strings. This information can be retrieved later by web-based CGI scripts with database queries. The webtool enables student groups to upload picture files and word documents into any part of their portfolios. The collection of portfolios is thus completely computerized. To insert links and to embed art, students need some basic html codes and relevant instruction is provided in computer training sessions early in the semester. The instructor sets a deadline for the submission of the CIITN portfolios (and the instructor may postpone the deadline at any time). Student groups can submit or upload data to the database until the deadline. Student groups have the option to submit draft projects "to the group", that is, they are viewable only by the group members. This function gives student groups privacy and protections against plagiarism. By the deadline, however, student groups must publish their portfolios at least "to the class" so that other groups can read their portfolios. They can also publish their portfolios "to the world" if they are willing to share their work with visitors to the CIITN website. 


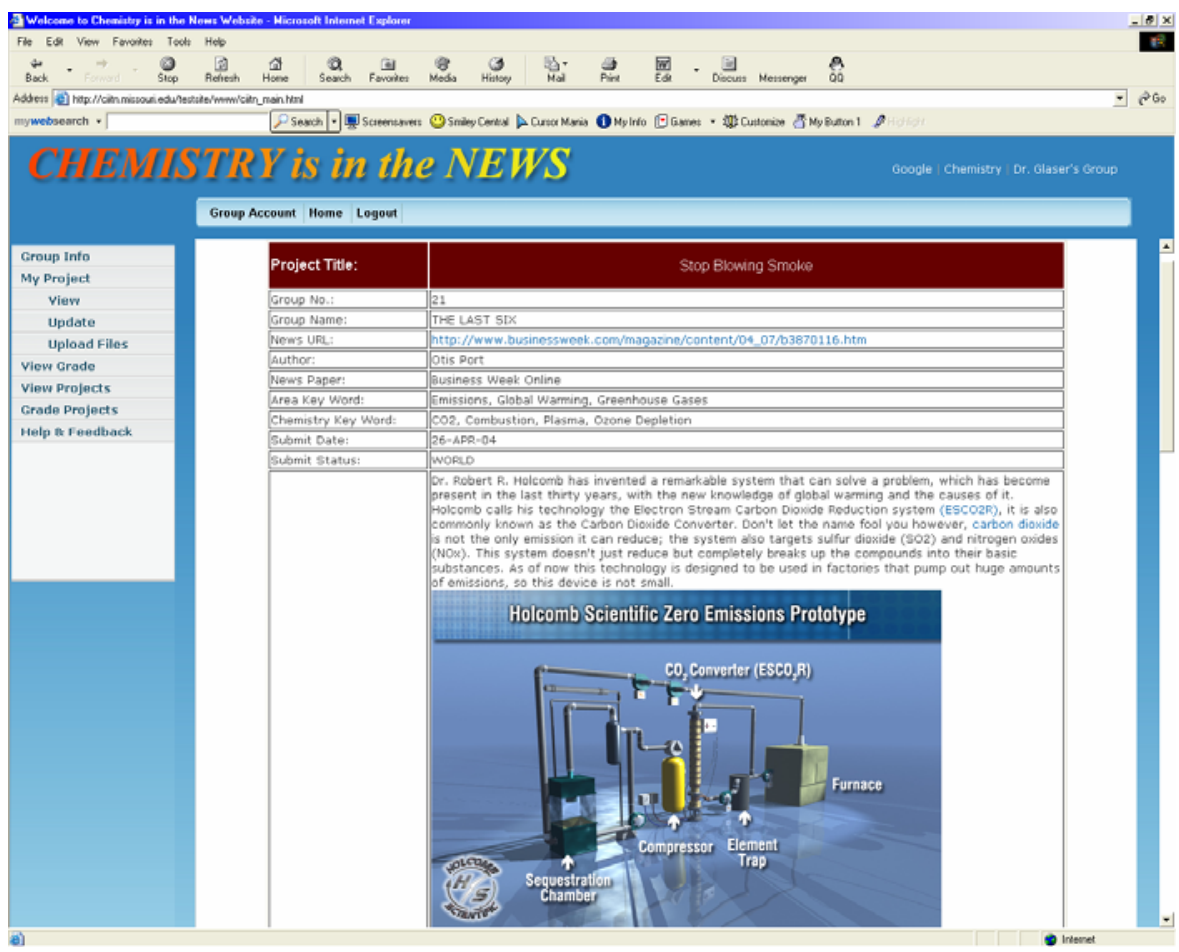

Figure 5: The Student Groups’ Web Interface.

After the deadline, students will be able to browse all the class projects online and the inter-group peer evaluation of the projects begins. The inter-group peer review is a "blind" review process in which student groups do not know which groups are reviewing their projects. The webtool provides detailed instructions and grading rubrics for the conduct of the constructive peer review. Reviewers are required to provide grades and explain the reasons for giving each score. The project score is the average of grades from the reviewing groups (usually three reviews). This averaging effectively minimizes the effects of unfair and/or incompetent and/or partial peer reviews.

Since it is one of the emphases of the CIITN project to teach students new ways of learning and thinking, there are two rounds of constructive peer evaluation of the group projects. The first round is to alert and guide student groups to possible improvement through constructive evaluation by their peers. The grade of the first round is not factored into the final grade of the group project. The CIITN database keeps the most updated version of a portfolio and subsequent revisions overwrite previous ones and the database also does keeps the reviews, grade and comment, from both rounds of peer review for the record.

In the past, some student groups did not complete the constructive peer evaluation on time and this problem has been solved as follows. The webtool was programmed so that student groups do not have access to their grades until they have completed their peer review assignments. This tactic also helps student groups to maintain objectivity while reviewing portfolios.

The functions designed for student groups enable all aspects of the online creation, collection and sharing of the CIITN portfolios, and the project peer evaluation process. Faculty/instructor(s) only need to assign the project and retrieve the project grades. 


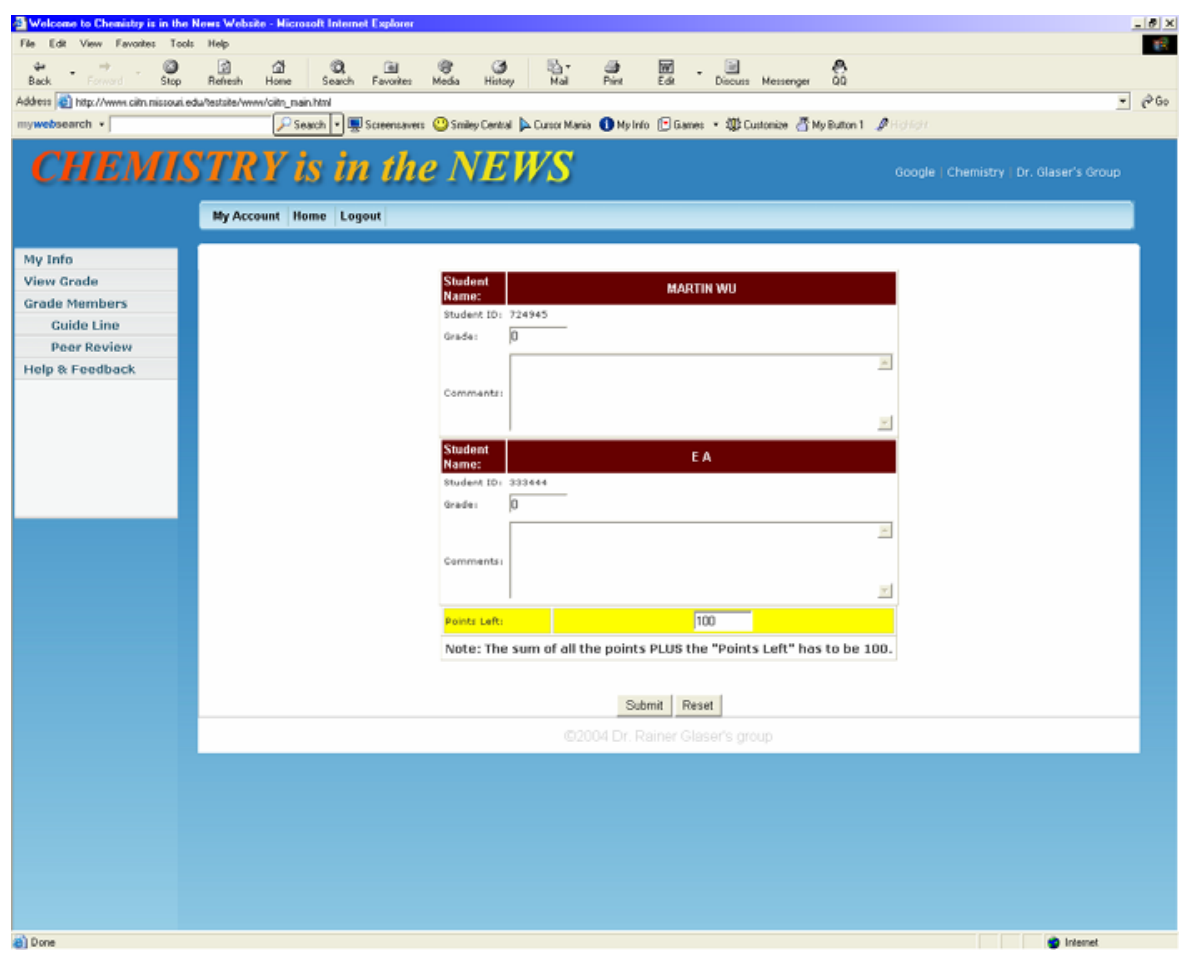

Figure 6: The Individual Student's Web Interface.

\section{Individual Student's Interface}

The CIITN implementation involves an intra-group peer evaluation where the members of a group evaluate each other to assess and reward the relative contributions of each group member. This evaluation process again is a "semi-blind" review. In contrast to the "blind" inter-group peer, students know their reviewers while they do not know which member wrote which particular review. Individual students need private accounts to perform this task.

After a student is added to a group as a group member, he/she will get a user name and password to access his/her personal account. The web interface of the student's individual account is shown in Figure 6. A student can change his/her password, but not the user name since the user name is his/her student ID and the primary key of the student table in the database.

Students have detailed guidelines to help them review their teammates. Unlike the grading scale for the inter-group peer evaluation, however, this guideline is rather qualitative. Students give just one overall score for every other teammate. The total available 100 points are to be distributed among all the teammates except for the person who is grading. For example, a student in a fivemember team will have 100 points to distribute among the four other teammates. Ideally, if all the team members equally contributed to the CIITN project, each member should get 25 from the grader. However, if some members are recognized as major contributors, they can be rewarded with more points. On the contrary, people who did not make adequate will get fewer points. The grader also has the option to leave some points not distributed if he/she does not think the total contributions from all other group members are satisfactory. The intra-group peer review score of a student is the sum of the score given by all his/her teammates divided by 100 . One should note that this grading method does create the possibility for the students with major contribution to achieve grades over $100 \%$. To ensure all students to complete the intra-group peer review, a student will get a zero for the CIITN project if he/she did not submit the review. 
The overall score of a student is the product of his/her intra-group peer evaluation score and his/her group’s CIITN project score from the inter-group peer evaluation.

\section{Results and Discussion}

The latest CIITN implementation, in the winter semester of 2004, involved CIITN level-5 (interstate) activities of students of two sophomore organic chemistry classes at the University of Missouri-Columbia, taught by Rainer Glaser, and the University of Colorado-Denver, taught by Susan Schelble. The most recent version, version 3, of the webtool was employed in this implementation serving 299 students, divided into 73 groups with 2-5 members each; most groups had 4 or 5 members. In computer training sessions for 5-6 groups at a time, teaching assistants provided instruction in the use of chemical structure drawing and modeling software, science writing (abstracts, synopsis, use of citations), access to online media and professional journals, search strategies and online research, and the use of the CIITN webtool. Aside from these computer training sessions, about two hours of regular class time were dedicated to the introduction of the CIITN Project, discussions of the science process, and instructions on peer review. The latter included a guest lecture on constructive peer review and the value of revision. These instructional activities along with the study of instructor-prepared CIITN portfolios, about one per week, provided an excellent preparation for the students to tackle the creation of their CIITN projects online during the last month of the course.

A preliminary evaluation of the effectiveness, functionality, and the student satisfaction with the CIITN webtool was carried out in the Winter Semester of 2004. A paper-based survey, using yes/no responses, was distributed at the end of the semester to the students at the University of Missouri. This survey was anonymous and also did not ask for any traceable information in order to be in compliance with the requirements of the approval Institutional Review Board for Project 1039285. Of the 224 students that participated in the course at the University of Missouri, 220 returned the survey. The user survey was adapted from one employed in a recent study by Whatley (2004) on the use of a software agent in support of team projects. The items of the questionnaire and survey results are given in Table 2. The positive responses on questions 1 and 4 indicate that computer-aided project creation does help students and that students recognize and embrace the benefits of using the webtool. The positive responses on questions 2 and 3, 82\% and $76 \%$, respectively, indicate that the successful design of the CIITN webtool and its conceptual propinquity to the pedagogical and organizational structure of the CIITN project. The layout of the interface clearly and directly connects with the corresponding built-in functionalities and proactively avoids confusion. The somewhat lower rating on question 5 (but still well over 50\%) suggests that in future, the functionality of the webtool should be combined with some features that improve the attractiveness of the environment.

As pointed our earlier in our discussion, an obvious advantage of a web interface compared with an independent software agent is that users of a web based interface do not have to install any software and do not need to get any special computer software training. The importance of this is illustrated by the overwhelming agreement (more than 97\%) of the students with the statement that "CIITN webtool is useful for the group project creation." This high level of user acceptance most likely reflects the convenience provided by the webtool and the students' familiarity with of the web interface. This result emphasizes that simplicity and/or familiarity are important issues for the success of the implementation of computer-assisted tools in education. 
Table 2: CIITN Webtool Users Survey and Results

\begin{tabular}{|l|c|c|}
\hline \multicolumn{1}{|c|}{ Survey Questions } & $\begin{array}{c}\text { Number of } \\
\text { "Yes” Re- } \\
\text { sponses }\end{array}$ & $\begin{array}{c}\text { Percentage } \\
\text { of "Yes" } \\
\text { Responses }\end{array}$ \\
\hline $\begin{array}{l}\text { 1. Did you find the webtool useful to facilitate the process of com- } \\
\text { pleting the group project? }\end{array}$ & 214 & 97.3 \\
\hline 2. Did you find the webtool easy to use? & 180 & 81.8 \\
\hline 3. Was it self-explanatory? & 166 & 75.5 \\
\hline 4. Do you like the concept of using the webtool for group projects? & 188 & 85.5 \\
\hline 5. Would you personally like to use this webtool? & 129 & 58.6 \\
\hline
\end{tabular}

\section{Conclusions}

A database supported web interface, the CIITN web portal, was developed to support online creation and peer review of team projects conducted as part of a science course at a major Midwestern state university. ICT competencies are intricately entwined with all aspects of the project from topic selection and creation to publication and evaluation. It is the strength of the CIITN project that science content and ICT activities are combined synergistically in order to promote greater literacy in both arenas. The concept and functionalities of the CIITN webtool can easily be adopted by other academic disciplines and other levels of education that involves team project creation and peer evaluation. Parties interested in using the CIITN webtool are encouraged to contact the authors.

\section{Acknowledgement}

We thank the National Science Foundation, the Camille \& Henry Dreyfus Foundation, the University of Missouri System, and the University of Missouri-Columbia for financial support. MU Information Access and Technology Services provide the database and web servers. Kathleen Carson offered valuable insights that contributed to shaping the pedagogical aspects of the CIITN Project. We also greatly appreciate feedback and contributions from the CIITN team and, in particular, from Brian Hodgen, Yongqiang Sui, Susan Schelble, and Eric Lupo.

\section{References}

Advisory Committee to the National Science Foundation Directorate for Education and Human Resources. (1996). NSF 96-139 -- SHAPING THE FUTURE: New Expectations for Undergraduate Education in Science, Mathematics, Engineering, and Technology. A Report on its Review of Undergraduate Education. Retrieved 2004 from http://www.ehr.nsf.gov/ehr/due/outreach/stf/publications.asp

Barka, K. M. \& Barka, L. H. (1996). Developing student speaking skills: A project/independent study in forensic science. Journal of Chemical Education, 73, 931-933.

Biehler, R. F. \& Snowman, J. (1986). Psychology applied to teaching (5 ${ }^{\text {th }}$ ed.). Boston, MA: Houghton Mifflin Company.

Bloom, B. S., Engelhart, M. D., Frost, E. J., Hill, W. H., \& Krathwohl, D. R. (1956). Taxonomy of educational objectives. Handbook I: Cognitive Domain. New York, NY: David McKay. 
Bodner, G., Klobuchar, M., \& Geelan, D. (2001). The many forms of constructivism. The Journal of Chemical Education, 78, 1107.

Bonwell, C.C. \& Eison, J. A. (1991). Active learning: Creating excitement in the classroom. ASHE-ERIC Higher Education Report No.1. Washington, DC: Association for the Study of Higher Education.

Borman, S. (2004, November 22). Chemistry in the news - Teaching chemistry in the context of news helps students see the real-world implications of science. Chemical and Engineering News, 82, 75-78.

Capri, A. (2001). Improvements in undergraduate science education using web-based instruction modules: The Natural Science Pages. Journal of Chemical Education, 78, 1709-1712.

Carnevale, D. (2003, January 31). The virtual lab experiment. The Chronicle of Higher Education, 49, p A30.

Chasteen, T. G. (2001). News from online: Teaching with chemical instrumentation on the web. Journal of Chemical Education, 78, 1144-1148.

Freeman, M. (1995). Peer assessment by groups of group work. Assessment and Evaluation in Higher Education, 20, 289-300.

Forsythe, C., Grose, E., \& Ratner, J. (1998). Human factors and web development. Mahwah, NJ: Lawrence Erlbaum Associates.

Glaser, R. (2003). Science communication for all. Chemistry International, 25, 3-6.

Glaser, R. \& Carson, K. (in press). Chemistry is in the news. Taxonomy of authentic news media based learning activities. International Journal of Science Education.

Glaser, R. \& Poole M. J. (1999). Organic chemistry online: Building collaborative learning communities through electronic communication tools. Journal of Chemical Education, 76, 699-703.

Hume, D., Carson, K., Hodgen, B., \& Glaser, R. (2004). Chemistry is in the news. Philosophy, pedagogy and assessment of authentic news media based learning activities. Manuscript submitted for publication.

Kelter, P. B.; Jacobitz, K.; Kean, E.; \& Hoesing, A. (1996). A chemistry course for elementary education majors - What is possible when the chemistry and education departments see eye to eye. Journal of Chemical Education, 73, 933-937.

Leslie, M. (2004). Chemistry behind the headlines. Science, 306, 1109.

O’Connor, B., Anderson, P., Bynum, M., Gaston, P., Guimaraes de Castro, M. H., Malyn-Smith, J., McGaw, B., Methia, R., \& Taylor, L. A. (2002). Digital transformation: A framework for ICT literacy. Princeton, NJ: Educational Testing Service.

Rafiq, Y. \& Fullerton, H. (1996). Peer assessment of group projects in civil engineering. Assessment and Evaluation in Higher Education, 21, 69-81.

Ramakrishnan, R.; \& Gehrke, J. (2000). Database management systems. McGraw-Hill.

Rudenstine, N. (1997). The Internet and education: A close fit. The Chronicle of Higher Education, p. A48.

Russell, A. A., Chapman, O. L., \& Wegner, P. A. (1998). Molecular science: Network-deliverable curricula. Journal of Chemical Education, 75, 578.

Stone, V. L., Bongiorno, R., Hinegardner, P. G., \& Williams, M. A. (2004). Delivery of web-based instruction using Blackboard: A collaborative project. Journal of the Medical Library Association, 92, 375377.

Taylor, P. C., Gilmer, P. J., \& Tobin, K. (Eds.) (2002). Transforming undergraduate science teaching. New York: Peter Lang.

Towns, M. H., \& Zielinski, T. J. (2004). Online chemistry modules: Interaction and effective faculty facilitation. Journal of Chemical Education, 81, 1058-1065. 
Whatley, J. (2004). An agent system to support student teams working online. Journal of Information Technology Education, 3, 53-63.

\section{Biographies}

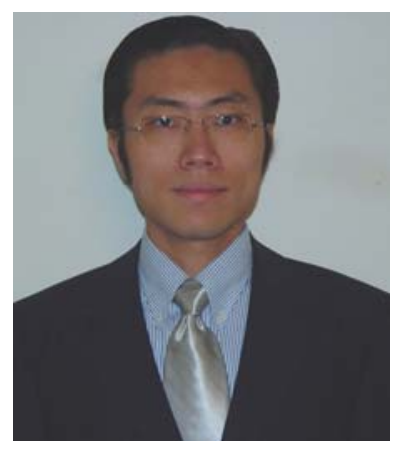

Dr. Zhengyu Wu was a graduate student in the Department of Chemistry, University of Missouri-Columbia, Columbia (USA), where he obtained his Ph.D. in 2004. He studied Chemistry and Computer Science at Peking University and Missouri. His graduate research includes topics in Theoretical, Computational, and Organic Chemistry, and Chemistry Education, and his studies have been published in over 10 papers. He programmed and maintained the CIITN webtool.

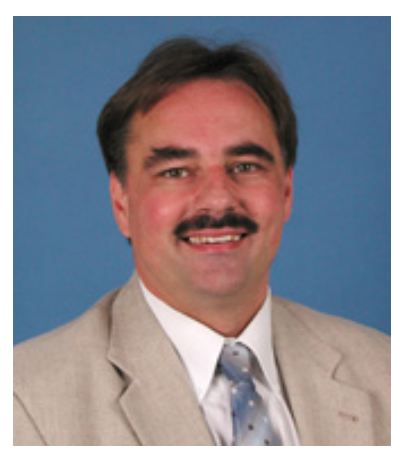

Dr. Rainer E. Glaser is Professor in Chemistry in the Department of Chemistry, University of Missouri-Columbia, Columbia, Missouri (USA). He studied Chemistry and Physics in Tübingen, Berkeley and Yale. His current research includes topics in Organic, Theoretical, and Materials Chemistry, Chemistry Education, and Astronomy. He has been interested in the development, implementation, and promotion of scientific teaching methods for over a decade and has implemented computer-assisted collaborative group activities in large lecture classes since 1997. In 2004, he became an AAAS Fellow. Homepage:

http://www.missouri.edu/ chemrg 